\title{
FOXC1 silencing inhibits the epithelial-to-mesenchymal transition of glioma cells: Involvement of $\beta$-catenin signaling
}

\author{
QINCHEN CAO $^{1}$, XINXIN WANG $^{2}$, YONGGANG SHI $^{1}$, MINGZHI ZHANG $^{3}$, JING YANG $^{1}$,

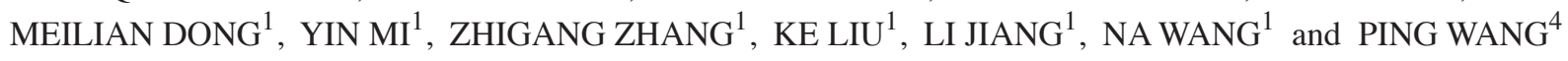

Departments of ${ }^{1}$ Radiation Therapy, ${ }^{2}$ Neurology and ${ }^{3}$ Oncology, The First Affiliated Hospital of Zhengzhou University, Zhengzhou, Henan 450052; ${ }^{4}$ Department of Radiation Therapy, Tianjin Medical University Cancer Institute and Hospital, Tianjin 300060, P.R. China

Received March 14, 2018; Accepted August 31, 2018

DOI: $10.3892 / \mathrm{mmr} .2018 .9650$

\begin{abstract}
Glioma is a type of malignant brain tumor. Forkhead box $\mathrm{C} 1$ (FOXC1) is a conserved transcription factor that is involved in tumorigenesis; however, the function of FOXC1 in glioma remains unclear. The present study aimed to investigate the effects of FOXC1 silencing on the epithelial-to-mesenchymal transition (EMT) of glioma cells. FOXC1-specific small interfering RNAs were employed to downregulate the expression levels of FOXC1 in glioma cells. The proliferation, migration and invasion of glioma cells were assessed by MTT assay, wound healing assay and Transwell assay. Western blot analysis was performed to reveal the effects of FOXC1 on EMT-associated proteins and $\beta$-catenin signaling. The results revealed that, following $\mathrm{FOXC1}$ silencing, the proliferation, migration and invasion of glioma cells were decreased. The expression levels of EMT-associated proteins were also affected. Further examination demonstrated that $\beta$-catenin signaling was involved in the effects of $\mathrm{FOXC1}$ on glioma cells. Previous results suggested that overexpression of $\beta$-catenin reversed the effects of FOXC1 silencing on glioma cells. The present study demonstrated that FOXC1 may regulate the EMT of glioma cells, potentially via $\beta$-catenin signaling. Therefore, FOXC1 may be a potential therapeutic target for the treatment of glioma.
\end{abstract}

\section{Introduction}

Glioma is one of the most common types of malignant tumor in the central nervous system, which accounts for $29 \%$ of

Correspondence to: Dr Mingzhi Zhang, Department of Oncology, The First Affiliated Hospital of Zhengzhou University, 1 East Jianshe Road, Zhengzhou, Henan 450052, P.R. China

E-mail: someonezhangmzh@126.com

Dr Yonggang Shi, Department of Radiation Therapy, The First Affiliated Hospital of Zhengzhou University, 1 East Jianshe Road, Zhengzhou, Henan 450052, P.R. China

E-mail: shiyong737@126.com

Key words: forkhead box $\mathrm{C} 1$, proliferation, migration, invasion, glioma, $\beta$-catenin all types of brain tumor and contributes to cancer-associated mortality rates (1). Characteristics of glioma are high incidence and mortality rates, high recurrence and low cure rates. It is difficult to diagnose and treat glioma at an early stage due to the lack of auxiliary examination indexes. Although advances have been made in the diagnostic and therapeutic strategies for glioma, the prognoses of patients with glioma remain poor, particularly for those with glioblastoma, with an estimated 2-year survival rate of $15 \%$ (2).

Epithelial-to-mesenchymal transition (EMT) is a biological process in which epithelial cells are transformed to mesenchymal-like cells. Throughout the EMT process, epithelial cells lose their connectivity to basement membranes and acquire improved migratory and invasive capabilities. EMT, which is regulated by complex networks, is an important process in development. It also serves important roles in the tumorigenic process, resulting in improvement of the migration and invasion of tumor cells (3-5).

Forkhead box (FOX) proteins are a class of conserved transcription factors, which are implicated in various biological and physiological processes. The dysregulation of FOX proteins is also implicated in tumor progression; therefore, FOX proteins are considered potential diagnostic markers or therapeutic targets for cancer $(6,7)$. As a member of the FOX protein family, FOXC1 is located on chromosome $6 \mathrm{p} 25$. FOXC1 contains a conserved forkhead domain, which binds upstream of target genes, thus promoting gene activation. FOXC1 has critical roles in physiological processes, including growth, development and differentiation (8-11). FOXC1 also serves important roles in pathological conditions and the dysregulation of FOXC1 additionally contributes to tumorigenesis. Previous evidence has revealed that FOXC1 is involved in tumor development (7). Notably, FOXC1 has been demonstrated to be overexpressed in breast cancer and lung cancer, and is correlated with the poor survival rates of these cancer types (12-15). Furthermore, FOXC1 has been reported to regulate the growth, metastasis and differentiation of several types of cancer (16-20). Therefore, FOXC1 is regarded as a potential biomarker for certain cancer types.

FOXC1 is associated with the proliferation and migration of various types of cancer $(15,21)$ and is regarded as an EMT inducer. It has previously been reported that FOXC1 
is highly expressed in glioma (22); however, to the best of our knowledge, there have been no previous studies on the association between FOXC1 and glioma. The present study aimed to examine the function of FOXC1 in glioma cells and to investigate the underlying mechanism.

\section{Materials and methods}

Materials. FOXC1 small interfering (si)RNA1 (target sequence: 5'-CCACTGCAACCTGCAAGCCAT-3'), FOXC1 siRNA2 (target sequence: 5'-GCCGCACCATAGCCAGGGCTT-3') and negative control (NC) siRNA (5'-TTCTCCGAACGTGTCACG TTT-3') were obtained from Shanghai GenePharma Co., Ltd. (Shanghai, China). $\beta$-catenin overexpression (OE) plasmid and empty vector were obtained from Addgene, Inc. (cat. no. 19286; Cambridge, MA, USA). Antibodies against FOXC1 (cat. no. 55365-1-AP), N-cadherin (cat. no. 22018-1-AP), E-cadherin (cat. no. 20874-1-AP), Vimentin (cat. no. 10366-1-AP), Snail (cat. no. 13099-1-AP), Twist (cat. no. 25465-1-AP), $\beta$-catenin (cat. no. 17565-1-AP) and c-myc (cat. no. 10828-1-AP) were purchased from Wuhan Sanying Biotechnology (Wuhan, China). Antibodies against phosphorylated (p)- $\beta$-catenin (cat. no. 4176) and GAPDH (cat. no. 2118) were purchased from Cell Signaling Technology, Inc. (Danvers, MA, USA).

Cell culture. U251 cells and SHG44 cells were obtained from Procell Life Science and Technology Co., Ltd. (Wuhan, China). U251 cells were grown in Dulbecco's modified Eagle's medium (Gibco; Thermo Fisher Scientific, Inc., Waltham, MA, USA) supplemented with $10 \%$ fetal bovine serum (FBS; Biological Industries, Kibbutz Beit Haemek, Israel). SHG44 cells were grown in RPMI-1640 medium (Gibco; Thermo Fisher Scientific, Inc.) supplemented with $10 \%$ FBS. All cells were cultured in a cell incubator at $37^{\circ} \mathrm{C}$ in an atmosphere containing $5 \% \mathrm{CO}_{2}$.

Transfection. Cells were seeded into a 6-well plate $\left(4 \times 10^{5}\right.$ cells/well). A total of $1 \mathrm{~h}$ prior to transfection, the medium was replaced with fresh serum-free medium. A total of $100 \mathrm{pmol}$ FOXC1 siRNA1, FOXC1 siRNA2 or negative control (NC) siRNA were transfected into cells using Lipofectamine ${ }^{\circledR} 2000$ (Invitrogen; Thermo Fisher Scientific, Inc.). After $4 \mathrm{~h}$ at $37^{\circ} \mathrm{C}$, the cell medium was replaced with fresh cell medium containing $10 \%$ FBS. Subsequently, the cells were subjected to reverse transcription-quantitative polymerase chain reaction (RT-qPCR) $24 \mathrm{~h}$ post-transfection or western blotting $48 \mathrm{~h}$ post-transfection. For co-transfection, cells were co-transfected with $1 \mu \mathrm{g}$ empty vector or $\beta$-catenin OE plasmid alongside $50 \mathrm{pmol} \mathrm{NC} \mathrm{siRNA}$ or FOXC1 siRNA2 using Lipofectamine ${ }^{\circledR} 2000$, as aforementioned.

$R T$ - $q P C R$. TRIpure lysis buffer (BioTeke Corporation, Beijing, China) was used to extract total RNA, according to the manufacturer's protocol. Subsequently, total RNA was reverse transcribed to cDNA using Super M-MLV reverse transcriptase (BioTeke Corporation) according to the manufacturer's protocol. FOXC1 mRNA expression levels were detected using the SYBR-Green method. SYBR Green was obtained from Beijing Solarbio Science and Technology Co., Ltd. (Beijing, China). The following primers were used: FOXC1 forward, 5'-CAGAACAGCATCCGCCAC A-3' and reverse, 5'-TGTTGTAGGAGTCCGGGTC-3'; and
GAPDH forward, 5'-GAAGGTCGGAGTCAACGGAT-3' and reverse, 5'-CCTGGAAGATGGTGATGGGAT-3'. The thermocycling conditions were $94^{\circ} \mathrm{C}$ for $5 \mathrm{~min}$; 40 cycles of $94^{\circ} \mathrm{C}$ for $10 \mathrm{sec}, 60^{\circ} \mathrm{C}$ for $20 \mathrm{sec}$, and $72^{\circ} \mathrm{C}$ for $30 \mathrm{sec}$; then $72^{\circ} \mathrm{C}$ for $2.5 \mathrm{~min}$ and $40^{\circ} \mathrm{C}$ for $1.5 \mathrm{~min}$; melting from $60^{\circ} \mathrm{C}$ to $94^{\circ} \mathrm{C}, 1^{\circ} \mathrm{C} / \mathrm{sec}$. The mRNA expression levels of FOXC1 were calculated using the $2^{-\Delta \Delta \mathrm{Cq}}$ method (23).

Western blot analysis. Proteins were extracted using radioimmunoprecipitation assay lysis buffer and protein concentration was measured using a Bicinchoninic Acid Protein Assay kit (both Beyotime Institute of Biotechnology, Shanghai, China). Subsequently, $40 \mu \mathrm{g}$ protein in each group were separated by 8,10 or $12 \%$ SDS-PAGE and the separated proteins were transferred onto polyvinylidene fluoride (PVDF) membranes (EMD Millipore, Billerica, MA, USA). The PVDF membranes were blocked with $5 \%$ skim milk or $1 \%$ bovine serum albumin (Biosharp, Hefei, China) at room temperature for $1 \mathrm{~h}$, and then incubated with FOXC1 (1:1,000), N-cadherin (1:1,000), E-cadherin $(1: 1,000)$, Vimentin $(1: 1,000)$, Snail $(1: 1,000)$, Twist $(1: 1,000), \beta$-catenin $(1: 1,000), p-\beta$-catenin $(1: 1,000)$, c-myc $(1: 1,000)$ and GAPDH antibodies $(1: 1,000)$ overnight at $4^{\circ} \mathrm{C}$. The PVDF membranes were rinsed and then incubated with corresponding horseradish peroxidase-labeled secondary antibodies (cat. no. A0208; 1:5,000; Beyotime Institute of Biotechnology) for $45 \mathrm{~min}$ at $37^{\circ} \mathrm{C}$. Subsequently, the PVDF membranes were visualized using an enhanced chemiluminescent kit (Beyotime Institute of Biotechnology). The target bands were scanned and analyzed by Gel-Pro-Analyzer software version 4.0 (Media Cybernetics, Inc., Rockville, MD, USA).

MTT assay. Cells were seeded in $96-$ well plates $\left(4 \times 10^{3}\right.$ cells in each well) and were transfected with NC siRNA, FOXC1 siRNA1 or FOXC1 siRNA2. MTT (Sigma-Aldrich; Merck KGaA, Darmstadt, Germany) at a final concentration of $0.5 \mathrm{mg} / \mathrm{ml}$ was added to each well at $12,24,36,48$ and $72 \mathrm{~h}$. After culturing for $4 \mathrm{~h}$ at $37^{\circ} \mathrm{C}, 150 \mu \mathrm{l}$ dimethyl sulfoxide (Sigma-Aldrich; Merck KGaA) was added to each well following the removal of cell medium. Absorbance was measured at $570 \mathrm{~nm}$ using a microplate reader (BioTek Instruments, Inc., Winooski, VT, USA).

Wound healing assay. Cells were seeded into a 6-well plate (4X10 ${ }^{5}$ cells/well) and were transfected with negative control siRNA, FOXC1 siRNA1 or FOXC1 siRNA2. After $24 \mathrm{~h}$, when the cell confluence reached $80 \%$, cells were treated with mitomycin C (1 $\mu \mathrm{g} / \mathrm{ml}$; Sigma-Aldrich; Merck KGaA) for $1 \mathrm{~h}$ at $37^{\circ} \mathrm{C}$. Subsequently, wounds were created on the surface of the cell monolayer with a $200-\mu 1$ pipette tip. Cells were cultured in a cell incubator and the images were captured under an inverted microscope with magnification, x100 at $0 \mathrm{~h}$ and $24 \mathrm{~h}$. The relative migration ratio was calculated as follows: Relative migration ratio=(incipient gap between two edges-migrated gap between two edges)/incipient gap between the two edges.

Transwell assay. Transwell inserts were purchased from Corning Incorporated (Corning, NY, USA). Matrigel was purchased from BD Biosciences (San Jose, CA, USA). A total of $4 \times 10^{3}$ cells in $200 \mu \mathrm{l}$ cell medium were added into Transwell inserts (precoated with Matrigel) and $800 \mu \mathrm{l}$ medium 

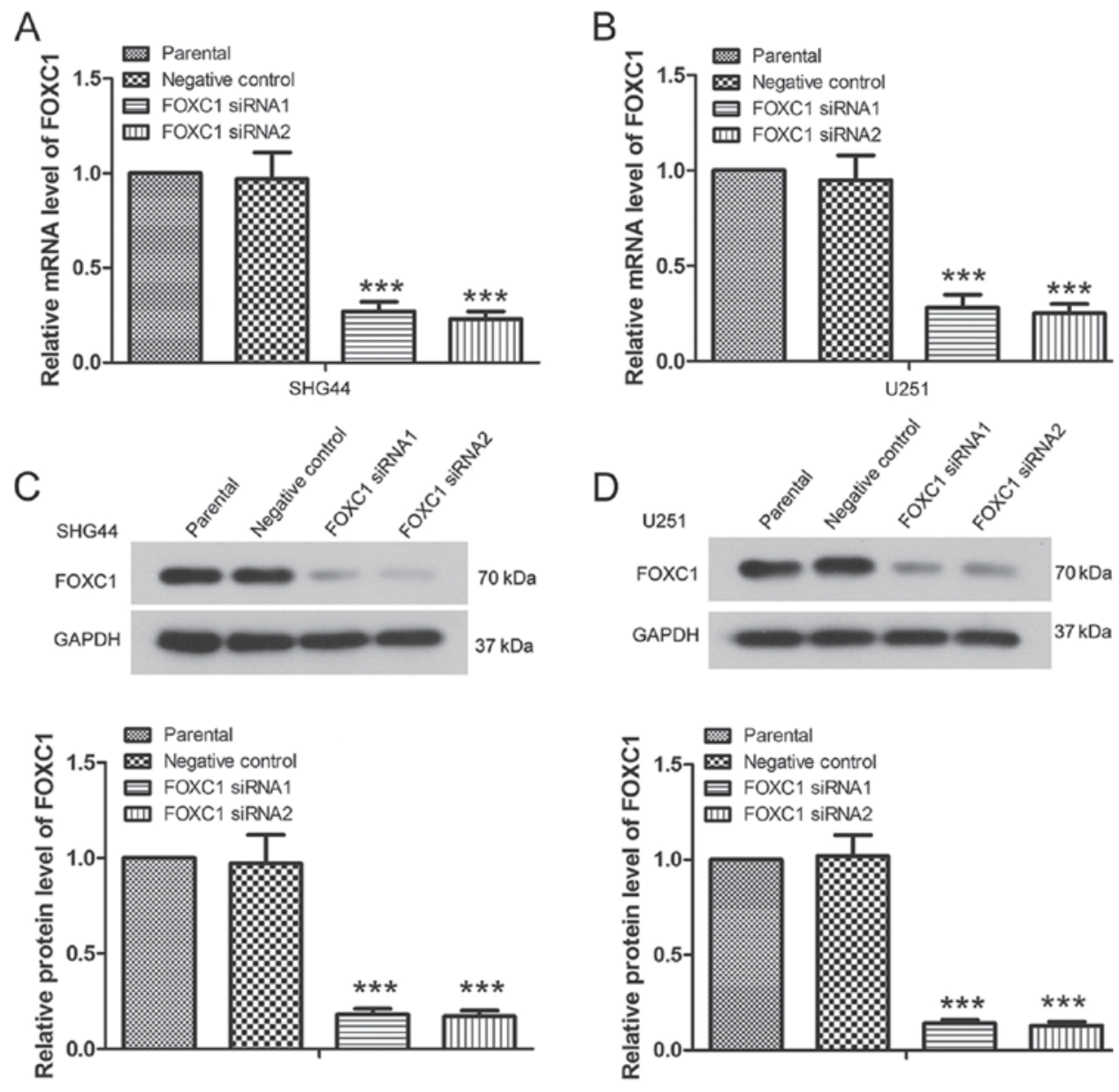

Figure 1. FOXC1 siRNAs effectively decrease the mRNA and protein expression levels of FOXC1. (A and B) Post-transfection with FOXC1 siRNA1 or FOXC1 siRNA2, the mRNA expression levels of FOXC1 were detected by reverse transcription-quantitative polymerase chain reaction. Relative mRNA expression levels of FOXC1 were normalized to GAPDH and calculated using the $2^{-\triangle \Delta C q}$ method. (C and D) Protein expression levels of FOXC1 in SHG44 and U251 cells were detected by western blot analysis post-transfection with FOXC1 siRNA1 or FOXC1 siRNA2. GAPDH served as the internal control. All experiments were repeated three times and the results are presented as the means \pm standard deviation. ${ }^{* * * *} \mathrm{P}<0.001$ vs. the negative control siRNA group. FOXC1, forkhead box C1; siRNA, small interfering RNA.

supplemented with $30 \%$ FBS was added into the lower chambers. Then the cells were transfected with the negative control siRNA, FOXC1 siRNA1 or FOXC1 siRNA2, or co-transfection with empty vector or $\beta$-catenin OE plasmid and negative control siRNA or FOXC1 siRNA2. Thereafter, the cells were cultured in a cell incubator and allowed to invade for $24 \mathrm{~h}$. After rinsing, cells on top of the membranes were removed. Cells that had invaded through the membranes were fixed with $4 \%$ paraformaldehyde at room temperature for $20 \mathrm{~min}$ and stained with $0.5 \%$ crystal violet for $5 \mathrm{~min}$. Images were captured under an inverted microscope (Motic Instruments, Richmond, BC, Canada) with a magnification, $\mathrm{x} 200$.

Immunofluorescence. Cells were seeded onto slides in 12-well plates $\left(5 \times 10^{4}\right.$ cells/well) and were transfected with negative control siRNA, FOXC1 siRNA1 or FOXC1 siRNA2. A total of $24 \mathrm{~h}$ post-transfection, cells were fixed with $4 \%$ paraformaldehyde for $15 \mathrm{~min}$ at room temperature and permeabilized with $0.1 \%$ Triton X-100 for $30 \mathrm{~min}$ at room temperature. The cells were blocked with goat serum (Beijing Solarbio Science and Technology Co., Ltd.) for $15 \mathrm{~min}$ at room temperature and were then incubated with a primary antibody against $\mathrm{N}$-cadherin (cat. no. 13116; 1:200; Cell Signaling Technology, Inc.) overnight at $4^{\circ} \mathrm{C}$. After rinsing, the cells were incubated with a Cy3-labeled secondary antibody (cat. no. A0516; 1:400; Beyotime Institute of Biotechnology) for $60 \mathrm{~min}$ at room temperature. Subsequently, the cells were rinsed, stained with DAPI (Sigma-Aldrich; Merck $\mathrm{KGaA}$ ), and observed under a fluorescence microscope (Olympus Corporation, Tokyo, Japan) with magnification, x400.

Statistical analysis. Each experiment was repeated three times and the results are presented as the means \pm standard deviation. Differences between groups were analyzed using a one-way or two-way analysis of variance, followed by Bonferroni's multiple comparison as a post-hoc test. $\mathrm{P}<0.05$ was considered to indicate a statistically significant difference.

\section{Results}

Silencing FOXCl inhibits the proliferation, migration and invasion of glioma cells. To examine the function of FOXC1 in glioma, FOXC1-specific siRNAs were used in the present study, and the expression levels of FOXC1 were detected in U251 and SHG44 cells. The RT-qPCR results revealed that, post-transfection with FOXC1 siRNA1 or FOXC1 siRNA2, the mRNA expression levels of FOXC1 were significantly 
A

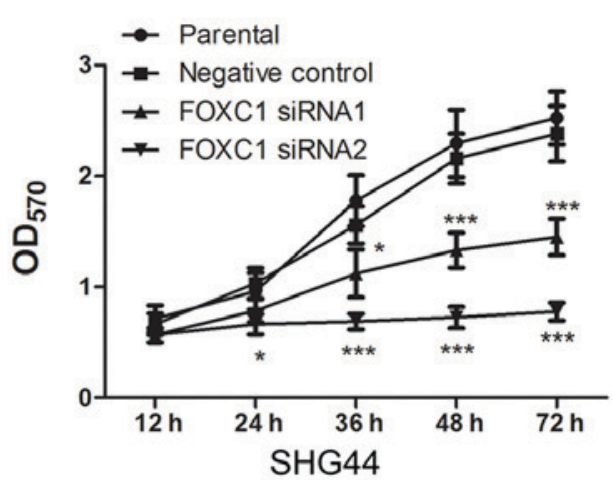

B

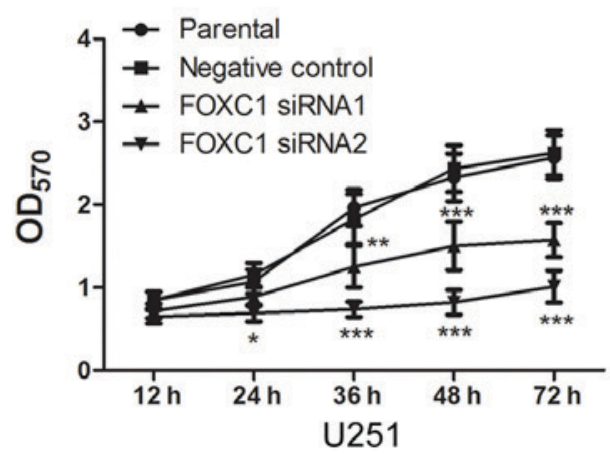

C

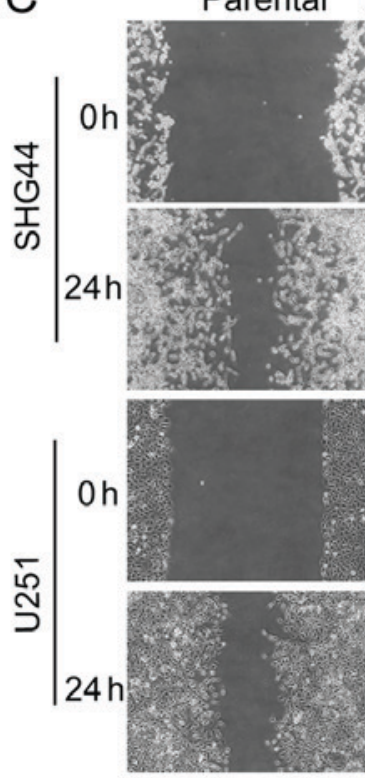

D
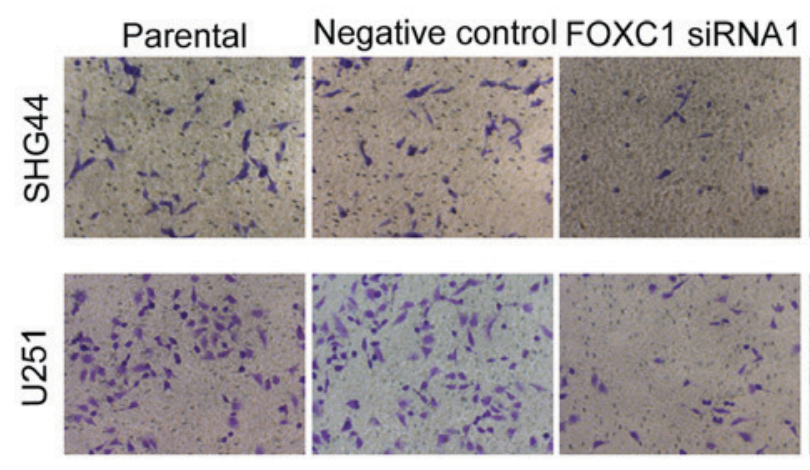
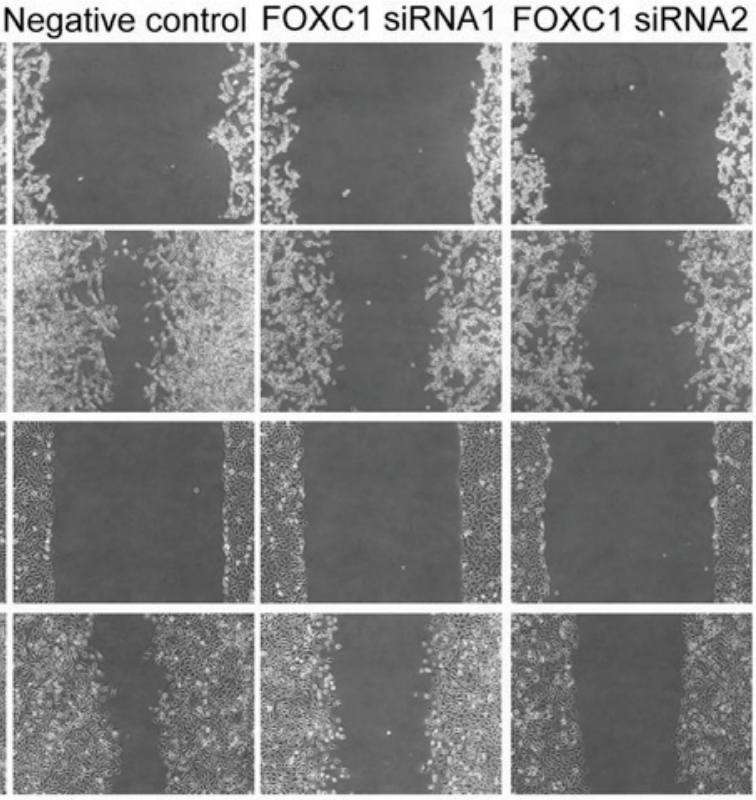

Negative control FOXC1 siRNA1 FOXC1 siRNA2
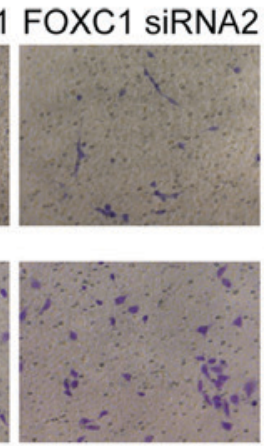
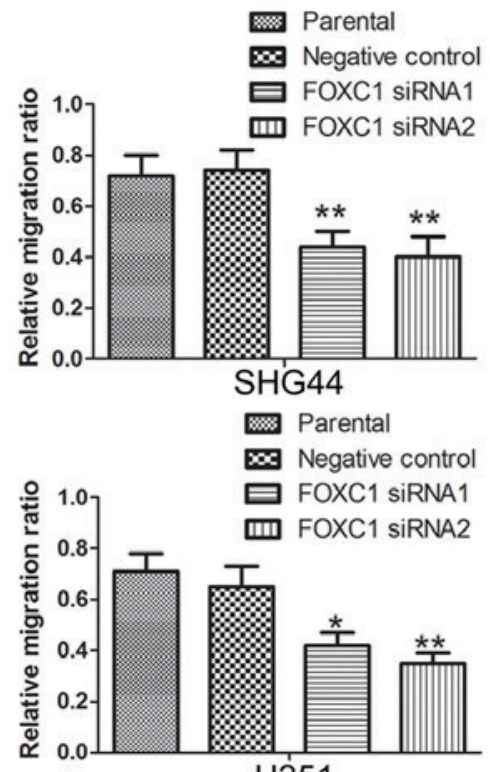

$\mathrm{U} 251$

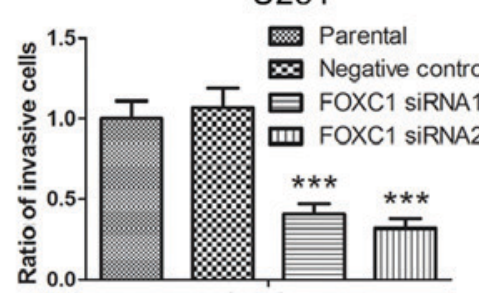

SHG44

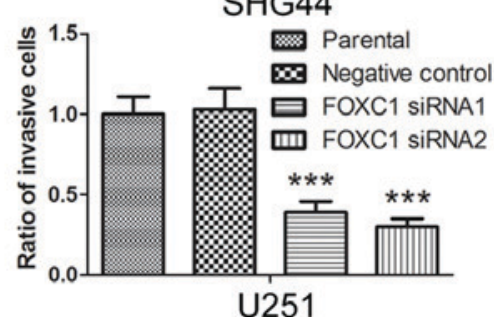

Figure 2. Silencing of FOXC1 inhibits the proliferation, migration and invasion of glioma cells. (A and B) Post-transfection with FOXC1 siRNA1 or FOXC1 siRNA2, the proliferation of SHG44 and U251 cells was assessed by an MTT assay. (C) Migratory capability of SHG44 and U251 cells was assessed by a wound healing assay, after which, the relative migration ratio was calculated. (D) Invasive capability of glioma cells was assessed using a Transwell assay, after which, the ratio of invasive cells was calculated. All experiments were repeated three times and the results are presented as the means \pm standard deviation. ${ }^{*} \mathrm{P}<0.05,{ }^{* *} \mathrm{P}<0.01,{ }^{* * * *} \mathrm{P}<0.001$ vs. the negative control siRNA group. FOXC1, forkhead box C1; OD, optical density; siRNA, small interfering RNA.

decreased (Fig. 1A and $\mathrm{B})(\mathrm{P}<0.001)$. The results of western blot analysis also revealed a significant decrease in the protein expression levels of FOXC1 in U251 cells and SHG44 cells in response to FOXC1 siRNA compared with in the NC siRNA group (Fig. 1C and $\mathrm{D})(\mathrm{P}<0.001)$. These results indicated that FOXC1 siRNA1 and FOXC1 siRNA2 effectively decreased FOXC1 expression.
The effects of FOXC1 silencing were also detected on the proliferation, migration and invasion of glioma cells. An MTT assay revealed that, post-transfection with FOXC1 siRNA1 or FOXC1 siRNA2, the proliferation of SHG44 and U251 cells was reduced compared with those transfected with the negative control siRNA (Fig. 2A and B). These results revealed that silencing FOXC1 inhibited the proliferation of glioma cells. 
A

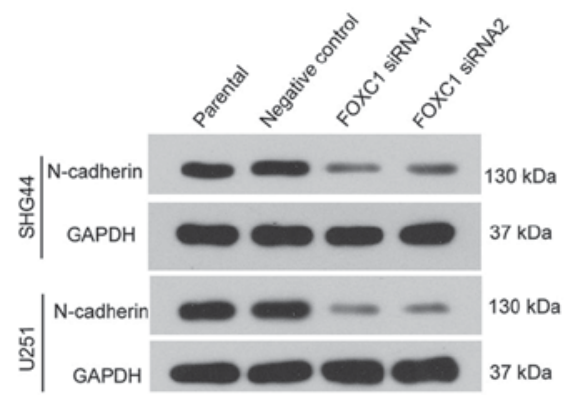

B
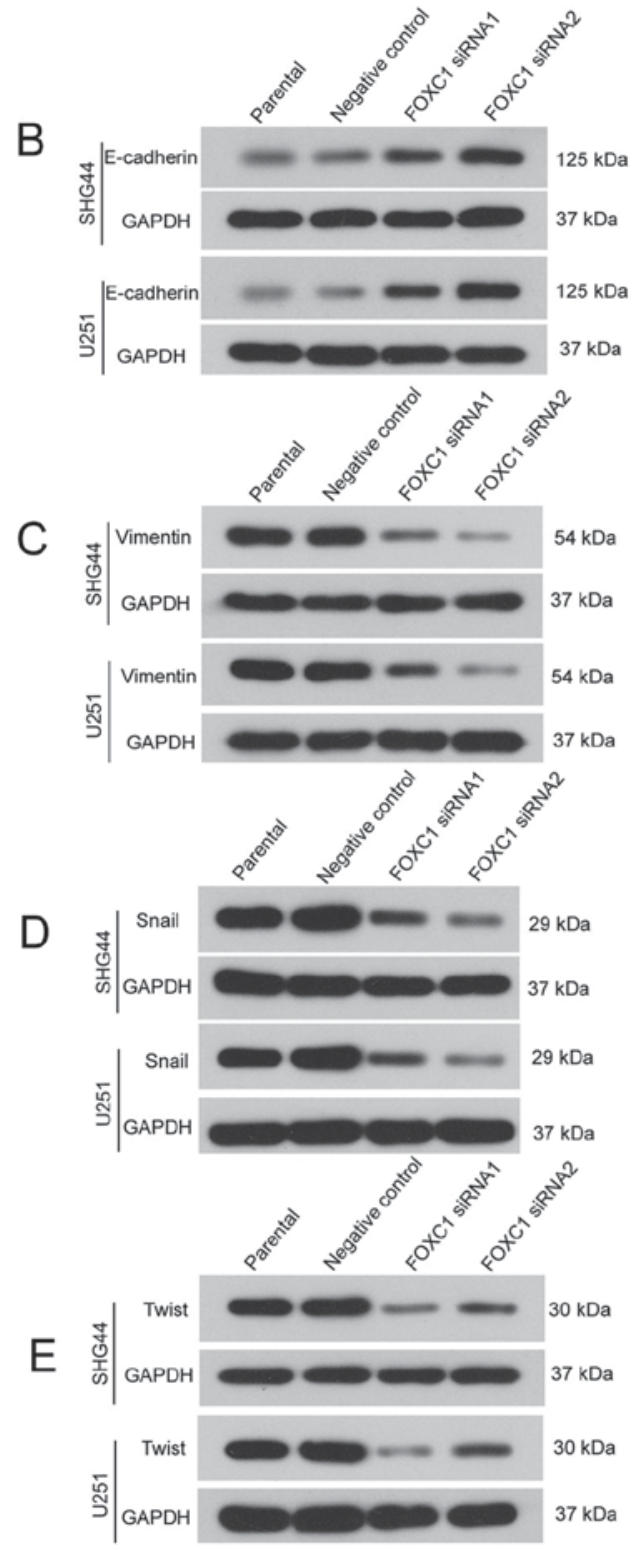
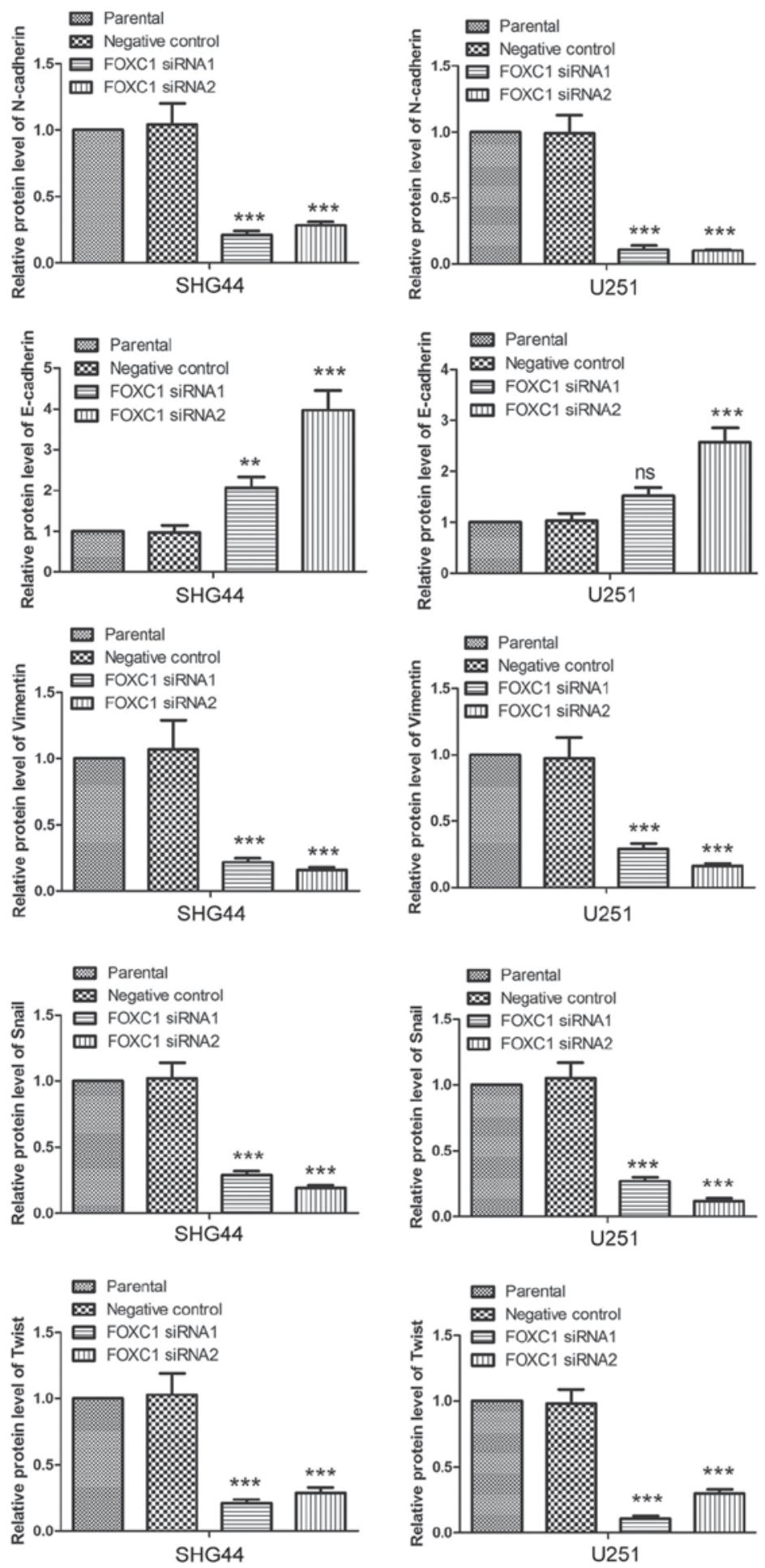

Figure 3. FOXC1 silencing modulates the protein expression levels of epithelial-to-mesenchymal transition-associated proteins. Protein expression levels of (A) N-cadherin, (B) E-cadherin, (C) Vimentin, (D) Snail and (E) Twist in SHG44 and U251 cells were detected by western blot analysis post-transfection with FOXC1 siRNA1 or FOXC1 siRNA2. GAPDH served as the internal control, and relative protein levels were calculated. All experiments were repeated three times and the results are presented as the means \pm standard deviation. ${ }^{* *} \mathrm{P}<0.01,{ }^{* * *} \mathrm{P}<0.001$ vs. the negative control siRNA group. FOXC1, forkhead box $\mathrm{C} 1$; ns, no significance; siRNA, small interfering RNA.

A wound healing assay demonstrated that, compared with the negative control siRNA group, the relative migration ratio of glioma cells was decreased by FOXC1 siRNA1 and FOXC1 siRNA2 (Fig. 2C). In addition, a Transwell assay revealed that the ratio of invasive cells was decreased by FOXC1 siRNA1 and FOXC1 siRNA2 compared with the negative control
siRNA (Fig. 2D). These results revealed that silencing FOXC1 inhibited the migration and invasion of glioma cells.

FOXCl modulates the expression of EMT-associated proteins. Since EMT contributes to the migration and invasion of cancer cells, the effects of FOXC1 silencing on the expression 

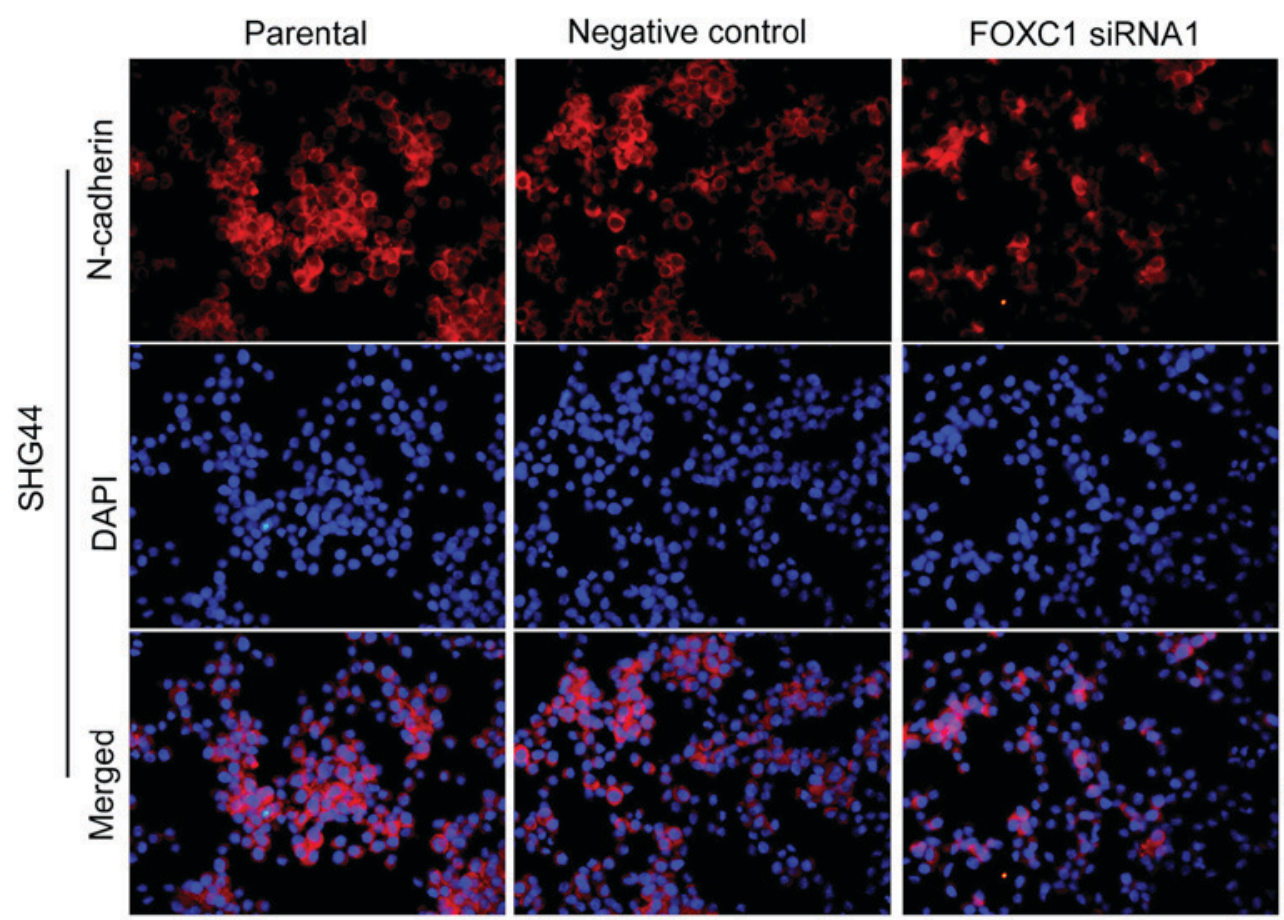

FOXC1 SIRNA2
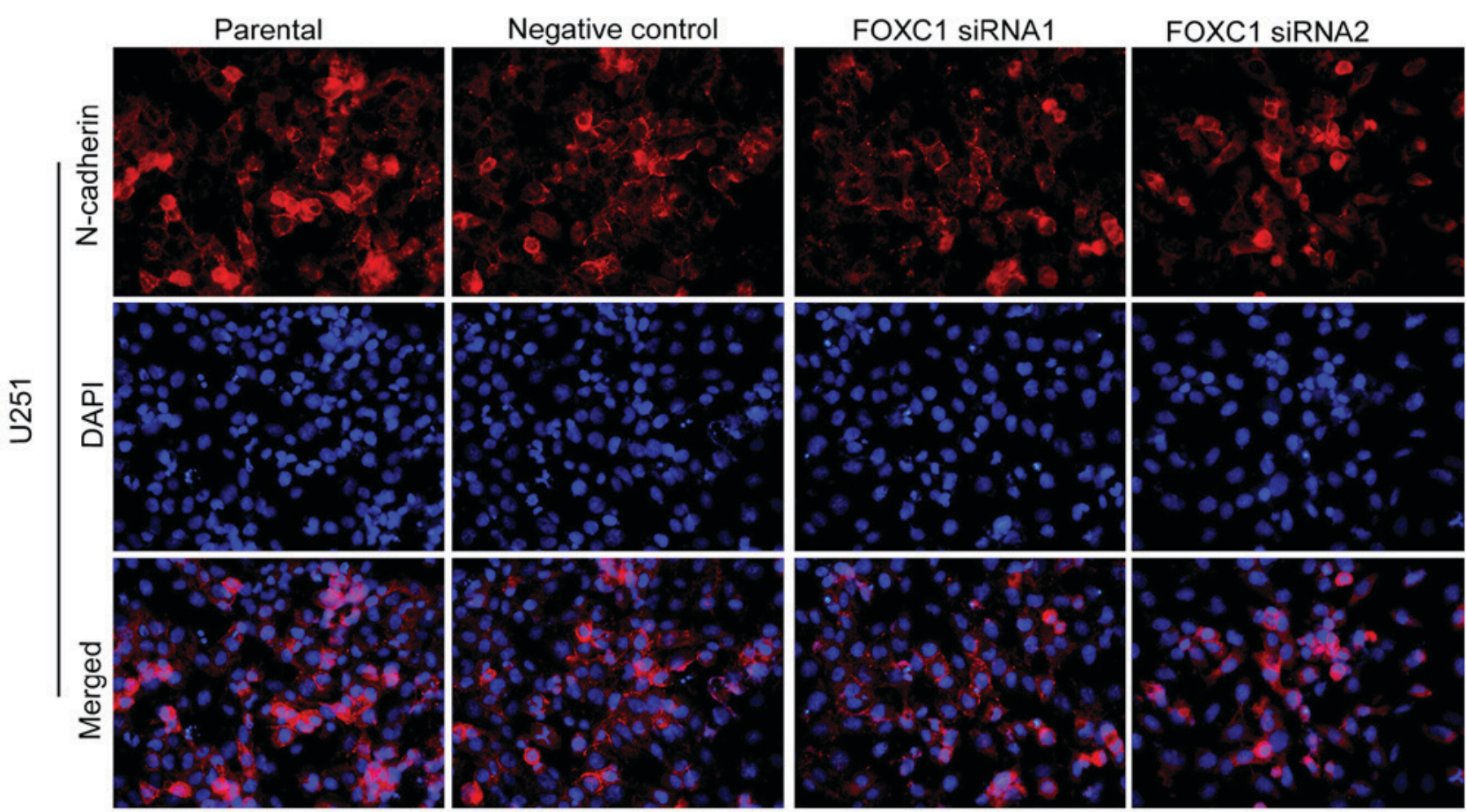

Figure 4. FOXC1 silencing influences the expression and distribution of N-cadherin. Immunofluorescence was performed to detect the expression and distribution of N-cadherin. Red fluorescence, N-cadherin; blue fluorescence, DAPI. FOXC1, forkhead box C1.

of EMT-associated proteins were detected by western blot analysis. As presented in Fig. 3A and B, in SHG44 and U251 cells, the expression levels of $\mathrm{N}$-cadherin were decreased by FOXC1 siRNAs, whereas the expression levels of E-cadherin were increased by FOXC1 silencing. In addition, the expression levels of Vimentin were decreased post-transfection with FOXC1 siRNAs (Fig. 3C), and the protein expression levels of Snail and Twist were also decreased (Fig. 3D and E). Furthermore, the expression and distribution of N-cadherin were detected by immunofluorescence. Consistent with the results of western blot analysis, immunofluorescence analysis revealed that, following silencing of FOXC1, $\mathrm{N}$-cadherin expression was reduced, particularly in the cell membranes (Fig. 4). These results revealed that FOXC1 silencing modulated the expression of EMT-associated proteins.

FOXC1 silencing affects $\beta$-catenin signaling. The expression and phosphorylation levels of $\beta$-catenin were detected by western blot analysis. Post-transfection with FOXC1 siRNA1 and FOXC1 siRNA2, the expression levels of $p$ - $\beta$-catenin were increased in SHG44 and U251 cells, whereas the protein 

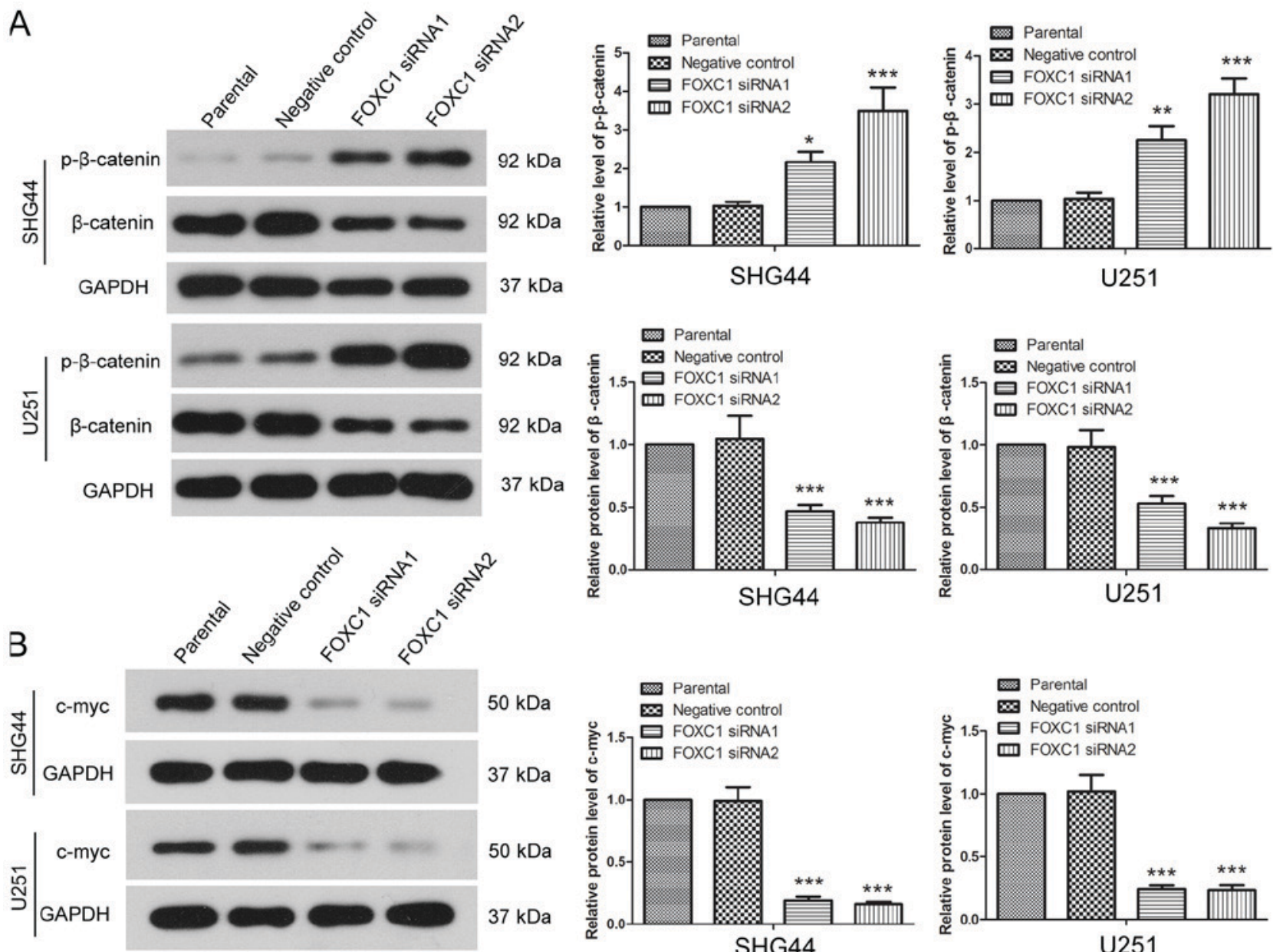

Figure 5. FOXC1 silencing affects $\beta$-catenin signaling. Post-transfection with FOXC1 siRNA1 or FOXC1 siRNA2, the expression levels of (A) total $\beta$-catenin and p- $\beta$-catenin, and (B) c-myc were detected in SHG44 and U251 cells by western blot analysis. GAPDH served as the internal control. The relative expression levels were calculated. All experiments were repeated three times and the results are presented as the means \pm standard deviation. ${ }^{*} \mathrm{P}<0.05,{ }^{* *} \mathrm{P}<0.01$, ${ }^{* * * *} \mathrm{P}<0.001$ vs. the negative control siRNA group. FOXC1, forkhead box C1; p, phosphorylated; siRNA, small interfering RNA.

expression levels of total $\beta$-catenin were significantly decreased compared with the negative control siRNA group (Fig. 5A). The protein expression levels of c-myc, which is a downstream target of $\beta$-catenin signaling, were also detected by western blotting. After silencing FOXC1, the expression levels of c-myc in SHG44 and U251 cells were decreased compared with the negative control siRNA group (Fig. 5B). These results revealed that silencing FOXC1 affected $\beta$-catenin signaling.

$\beta$-catenin signaling is involved in the effects of $\mathrm{FOXC1}$ silencing. Since FOXC1 silencing inhibited $\beta$-catenin signaling, a $\beta$-catenin $\mathrm{OE}$ plasmid was used in the present study. $\beta$-catenin OE plasmid and FOXC1 siRNA were co-transfected into cells, and the protein expression levels of $\beta$-catenin, $p$ - $\beta$-catenin and c-myc were detected by western blot analysis. As presented in Fig. 6, following OE of $\beta$-catenin, the protein expression levels of $\beta$-catenin were increased, whereas the expression levels of $p$ - $\beta$-catenin were decreased compared with the negative control group. Co-transfection with $\beta$-catenin OE plasmid and FOXC1 siRNA increased the expression levels of $\beta$-catenin, but decreased the levels of $\mathrm{p}$ - $\beta$-catenin compared with the empty vector and negative control siRNA group (Fig. 6A). In addition, co-transfection with $\beta$-catenin OE plasmid and FOXC1 siRNA increased the protein expression levels of c-myc compared with the empty vector and negative control siRNA group (Fig. 6B), indicating that co-transfection with $\beta$-catenin $\mathrm{OE}$ and FOXC1 siRNA enhanced the activation of $\beta$-catenin signaling. However, our previous data (Fig. 5) demonstrated that FOXC1 silencing alone suppressed $\beta$-catenin signaling, which was distinctly different from the effects of co-transfection with $\beta$-catenin $\mathrm{OE}$ and FOXC1 siRNA, suggesting that $\beta$-catenin OE may reverse the effects of FOXC1 silencing on $\beta$-catenin signaling.

Following co-transfection with $\beta$-catenin OE plasmid and FOXC1 siRNA, the invasion of SHG44 cells and U251 cells was assessed using a Transwell assay. $\beta$-catenin OE enhanced the invasive capability of SHG44 and U251 cells. However, following co-transfection with $\beta$-catenin $\mathrm{OE}$ and FOXC1 siRNA, the invasive capability of SHG44 and U251 cells demonstrated no significant difference compared with cells co-transfected with the empty vector and negative control siRNA (Fig. 7A). Our previous data in Fig. 2 showed that FOXC1 silencing alone inhibited the invasion of glioma cells. These results indicated that $\beta$-catenin OE may abolish the effects of FOXC1 silencing on the invasion of glioma cells. Additionally, compared with the empty vector and negative control siRNA group, the expression levels of $\mathrm{N}$-cadherin were increased and the expression levels of E-cadherin were decreased 


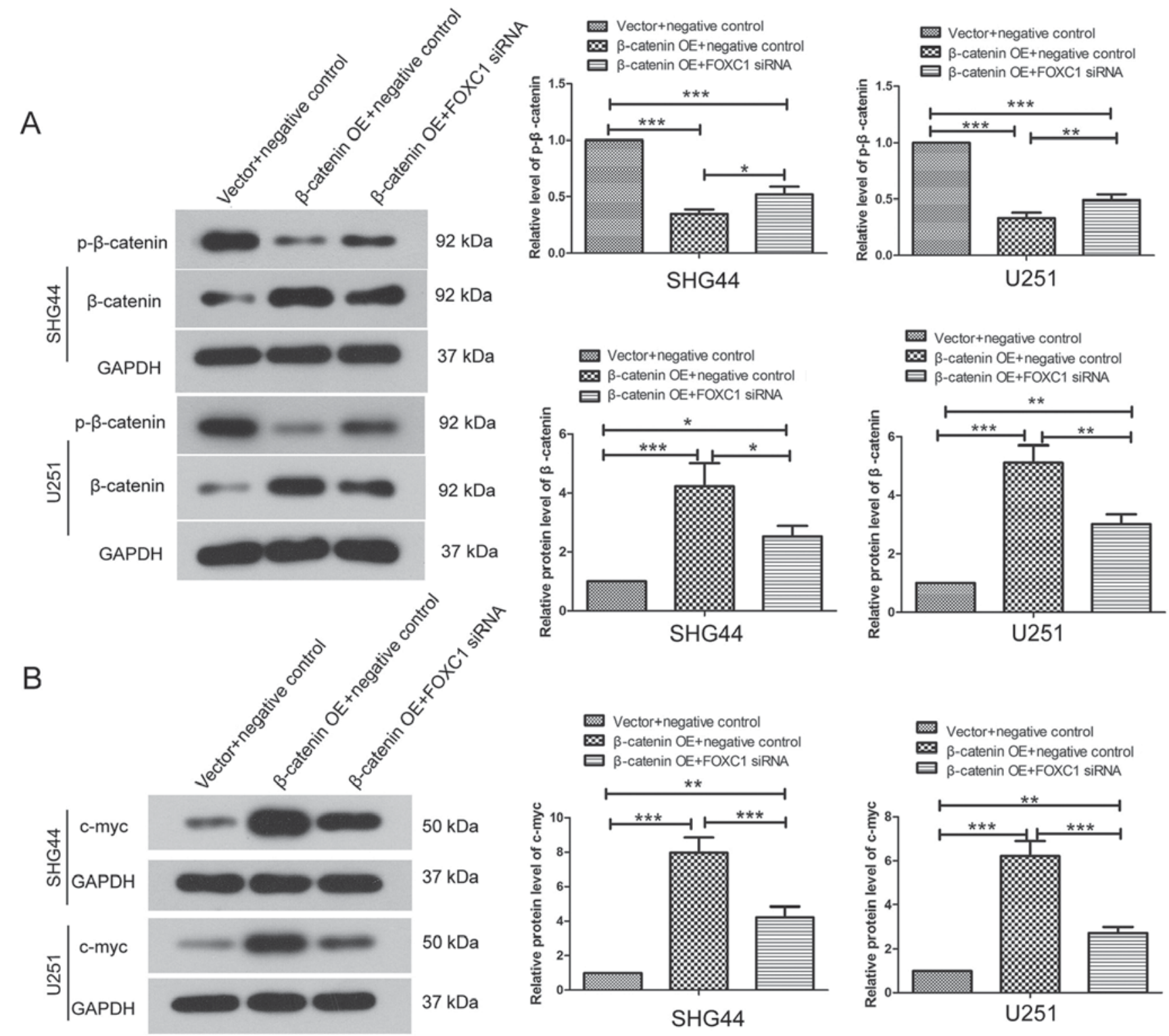

Figure 6. $\beta$-catenin OE eliminates the effects of FOXC1 silencing on $\beta$-catenin signaling. Following co-transfection with $\beta$-catenin $\mathrm{OE}$ plasmid and FOXC1 siRNA, the expression levels of (A) $\beta$-catenin and p- $\beta$-catenin, and (B) c-myc were detected in SHG44 and U251 cells by western blot analysis, with GAPDH as the internal control. Each experiment was repeated three times. The results are presented as the means \pm standard deviation. ${ }^{*} \mathrm{P}<0.05,{ }^{* *} \mathrm{P}<0.01,{ }^{* * *} \mathrm{P}<0.001$. FOXC1, forkhead box C1; OE, overexpression; siRNA, small interfering RNA.

following co-transfection with $\beta$-catenin OE and FOXC1 siRNA (Fig. 7B and C). However, our previous data (Fig. 3) demonstrated that FOXC1 silencing alone decreased that levels of N-cadherin and increased the levels of E-cadherin. These results provide further evidence supporting the hypothesis that $\beta$-catenin signaling is involved in the inhibitory effects of FOXC1 silencing on the EMT of glioma cells.

\section{Discussion}

Glioma is a type of malignant brain cancer, which is difficult to diagnose and cure at an early stage. FOXC1 has been revealed to be highly expressed in glioma $(22,24)$. In the present study, it was demonstrated that silencing FOXC1 inhibited the proliferation, migration and invasion of glioma cells. Further experiments revealed that $\beta$-catenin signaling was involved in the effects of FOXC1 silencing.
Growth of cancer cells is necessary for tumorigenesis. In numerous cancer types, FOXC1 functions as an oncogene; silencing $\mathrm{FOXC1}$ inhibits the proliferation of cancer cells $(15,21,25,26)$, whereas OE of FOXC1 promotes the proliferation of cancer cells $(19,27)$. In the present study, silencing FOXC1 was revealed to suppress the proliferation of glioma cells, indicating that $\mathrm{FOXC1}$ may function as an oncogene and promote the growth of glioma. The cell cycle is a crucial factor impacting cancer cell growth. FOXC1 silencing has been revealed to arrest the cell cycle of non-small-cell lung carcinoma cells at the $\mathrm{G}_{0} / \mathrm{G}_{1}$ phase and regulate cyclin D1 expression levels (15). FOXC1 also exerts effects on cancer cell apoptosis; knockdown of FOXC1 induces apoptosis in cervical cancer and endometrial cancer $(25,26)$. These findings indicated that the effects of FOXC1 silencing on glioma cell growth may be associated with its effects on the cell cycle and apoptosis of glioma. However, future studies investigating this implication are required. 

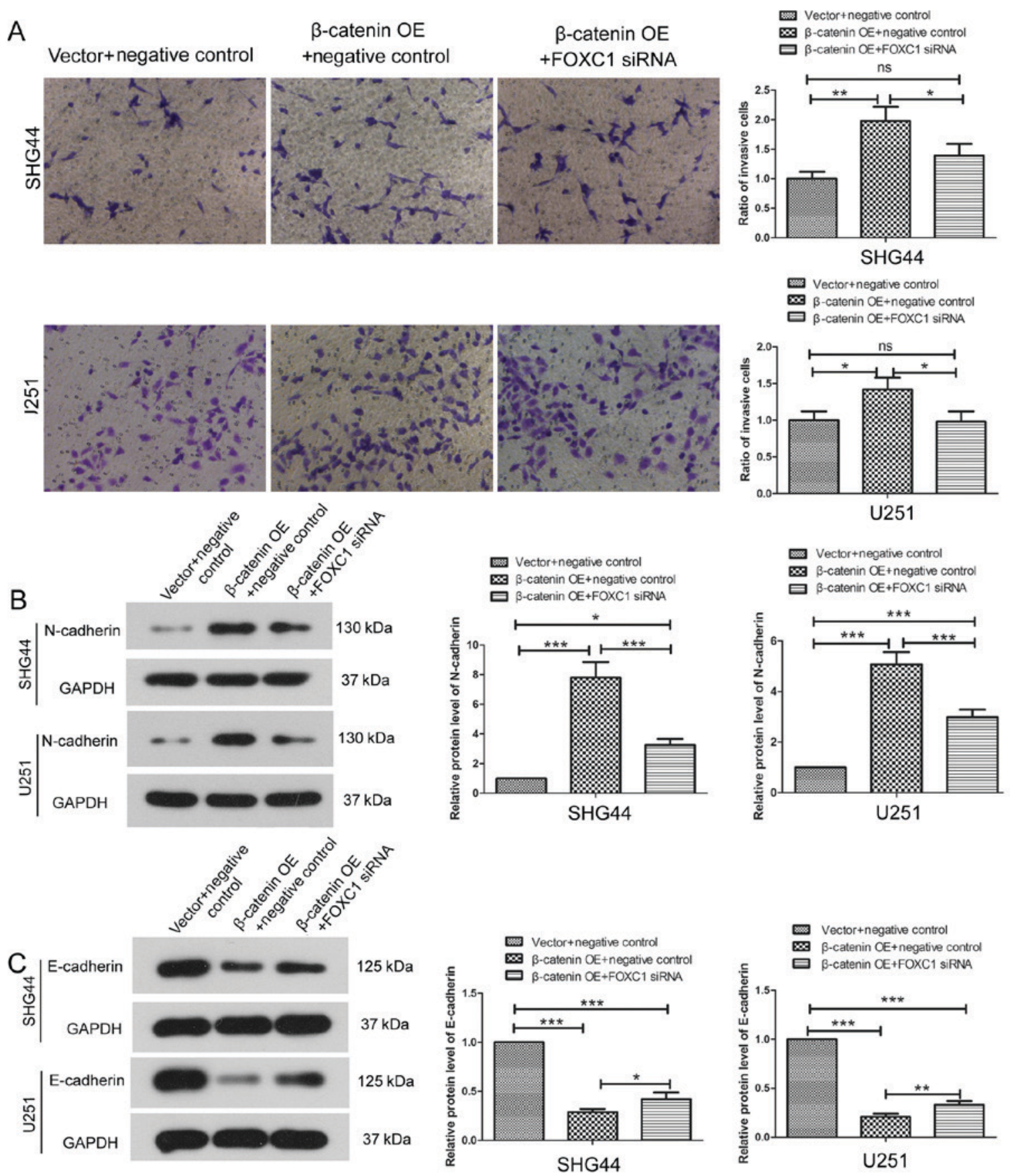

Figure 7. $\beta$-catenin $\mathrm{OE}$ abrogates the effects of FOXC1 silencing on the epithelial-to-mesenchymal transition of glioma cells. (A) Following co-transfection with $\beta$-catenin OE plasmid and FOXC1 siRNA, the invasion of SHG44 cells and U251 cells was assessed using a Transwell assay. Protein expression levels of (B) N-cadherin and (C) E-cadherin were assessed by western blot analysis following co-transfection with $\beta$-catenin OE plasmid and FOXC1 siRNA. GAPDH served as the internal control. All experiments were repeated three times and the results are presented as the means \pm standard deviation. ${ }^{*} \mathrm{P}<0.05,{ }^{* * *} \mathrm{P}<0.01$, ${ }^{* * *} \mathrm{P}<0.001$. FOXC1, forkhead box C1; ns, no significance; OE, overexpression; siRNA, small interfering RNA.

Migration and invasion additionally contribute to tumor development. The invasion of glioblastoma into adjacent normal tissues often results in incomplete resection. Liu et al (22) revealed that, through targeting FOXC1, microRNA-133 is able to inhibit the proliferation and invasion of glioma, indicating that FOXC1 may function as an oncogene in glioma. In the present study, silencing FOXC1 was revealed to inhibit the migration and invasion of glioma cells, indicating that $\mathrm{FOXC1}$ may regulate the metastasis of glioma. The present study provided direct evidence to suggest that FOXC1 performs as an oncogene in glioma cells. Consistently, the expression of FOXC1 is positively correlated with lymph node metastasis and the distant metastasis of nasopharyngeal cancer (18). FOXC1 also affects the migration and invasion of cervical cancer, endometrial cancer, osteosarcoma and melanoma $(19,21,25-27)$. The results of the present study verified the hypothesis that FOXC1 functions as an oncogene in glioma at the cellular level; however, a lack of in vivo data is a limitation of this study.

EMT is a process that enables epithelial cells to lose their cell-cell adhesion, and gain migratory and invasive properties. EMT also serves a crucial role in tumor metastasis and is regarded 
as a crucial function for cancer cells to escape from primary sites (28). N-cadherin is a cell-cell adhesion glycoprotein. It is able to facilitate transendothelial migration and is regarded as a marker of mesenchymal cells. E-cadherin is a component of an adhesion complex located in adherens junctions, and is regarded as a marker of epithelial cells. Dysregulation of E-cadherin results in the disintegration of adherens junctions (29). Vimentin is responsible for stabilization of the cytoskeleton, and Snail and Twist are regulators of E-cadherin and N-cadherin. All of these proteins serve important roles in the EMT process. The results of the present study revealed that these proteins, which are closely associated with EMT, were modulated by FOXC1 silencing, indicating that FOXC1 exerts effects on the EMT of glioma cells, which may contribute to its effects on the metastasis of glioma. Consistent with the present study, in other types of cancer, FOXC1 also contributes to the process of EMT $(17,20,21)$. In addition, throughout the EMT process, FOXC1 regulates the microvascular invasion of hepatocellular carcinoma (30).

The Wnt/ $\beta$-catenin pathway is involved in the regulation of numerous biological processes (31) and has been implicated in various malignancies $(32,33)$. The accumulation and nuclear translocation of $\beta$-catenin is a vital event in the activation of Wnt signaling. Nuclear $\beta$-catenin serves an important role in tumorigenesis; it has been reported that the expression levels of nuclear $\beta$-catenin, and its downstream targets cyclin D1 and c-Myc, are increased in glioma tissues and cell lines (34), and are associated with the proliferation and apoptosis of glioma cells $(35,36)$. In the present study, it was revealed that FOXC1 silencing alone suppressed $\beta$-catenin signaling, however, co-transfection of $\beta$-catenin OE and FOXC1 siNRA enhanced the activation of $\beta$-catenin signaling, indicating that the $\mathrm{OE}$ of $\beta$-catenin abolished the effects of FOXC1 silencing, thus it was concluded that $\beta$-catenin signaling may be implicated in the effects of FOXC1 on glioma. FOXC1 mutations may also result in a reduction of endothelial Wnt signaling (37). Furthermore, it has been demonstrated that there is a $\beta$-catenin binding site near the transcriptional start site of FOXC1, and $\beta$-catenin is able to directly regulate the transcription of FOXC1 (38). Therefore, the regulatory association between FOXC 1 and $\beta$-catenin requires further exploration. In addition to $\beta$-catenin signaling, alternative signaling pathways, including phosphoinositide 3-kinase/protein kinase $\mathrm{B}$ and nuclear factor- $\kappa \mathrm{B}$, are also involved in the effects of FOXC1 in cancer. Whether these signaling pathways are additionally implicated in the effects of FOXC1 on glioma remains unclear and requires further investigation $(16,19,21)$.

In conclusion, silencing FOXC1 was demonstrated to suppress the proliferation, migration and invasion of glioma cells. Further study revealed that $\beta$-catenin signaling was implicated in the function of FOXC1. The present study is the first, to the best of our knowledge, to provide direct evidence to suggest that FOXC1 functions as an oncogene in glioma cells. The present study indicated that silencing FOXC1 may be considered a potential therapeutic method for glioma; however, further investigation is required.

\section{Acknowledgements}

Not applicable.

\section{Funding}

The present study was supported by the National Natural Science Foundation of China (grant no. 81570203) and the Scientific Research Initiation Foundation for Youth of the First Affiliated Hospital of Zhengzhou University (grant no. 161032; Zhengzhou, China).

\section{Availability of data and materials}

All data generated or analyzed during this study are included in this published article.

\section{Authors' contributions}

QC, MZ and YS contributed to the study design, experiment performance and manuscript writing. XW, JY, MD, YM, ZZ, $\mathrm{KL}, \mathrm{LJ}, \mathrm{NW}$ and $\mathrm{PW}$ contributed to the performance of the experiments.

\section{Ethics approval and consent to participate}

Not applicable.

\section{Patient consent for publication}

Not applicable.

\section{Competing interests}

The authors declare that they have no competing interests.

\section{References}

1. Ostrom QT, Gittleman H, Fulop J, Liu M, Blanda R, Kromer C, Wolinsky Y, Kruchko C and Barnholtz-Sloan JS: CBTRUS statistical report: Primary brain and central nervous system tumors diagnosed in the united states in 2008-2012. Neuro Oncol 4 (Suppl 17): iv1-iv62, 2015.

2. Ho VK, Reijneveld JC, Enting RH, Bienfait HP, Robe P, Baumert BG, Visser O and Dutch Society for Neuro-Oncology (LWNO): Changing incidence and improved survival of gliomas. Eur J Cancer 50: 2309-2318, 2014.

3. Brabletz T, Kalluri R, Nieto MA and Weinberg RA: EMT in cancer. Nat Rev Cancer 18: 128-134, 2018.

4. Lamouille S, Xu J and Derynck R: Molecular mechanisms of epithelial-mesenchymal transition. Nat Rev Mol Cell Biol 15: 178-196, 2014.

5. Thiery JP, Acloque H, Huang RY and Nieto MA: Epithelial-mesenchymal transitions in development and disease. Cell 139: 871-890, 2009.

6. Myatt SS and Lam EW: The emerging roles of forkhead box (Fox) proteins in cancer. Nat Rev Cancer 7: 847-859, 2007.

7. Han B, Bhow mick N, Qu Y, Chung S, Giuliano AE and Cui X: FOXC1: An emerging marker and therapeutic target for cancer. Oncogene 36: 3957-3963, 2017.

8. Seo S, Fujita H, Nakano A, Kang M, Duarte A and Kume T: The forkhead transcription factors, foxc1 and foxc2, are required for arterial specification and lymphatic sprouting during vascular development. Dev Biol 294: 458-470, 2006.

9. Sun J, Ishii M, Ting MC and Maxson R: Foxc1 controls the growth of the murine frontal bone rudiment by direct regulation of a Bmp response threshold of Msx2. Development 140: 1034-1044, 2013.

10. Bin L, Deng L, Yang H, Zhu L, Wang X, Edwards MG, Richers B and Leung DY: Forkhead box $\mathrm{C} 1$ regulates human primary keratinocyte terminal differentiation. PLoS One 11: e0167392, 2016. 
11. Mirzayans F, Lavy R, Penner-Chea J and Berry FB: Initiation of early osteoblast differentiation events through the direct transcriptional regulation of Msx 2 by FOXC1. PLoS One 7: e49095, 2012.

12. Wang J, Xu Y, Li L, Wang L, Yao R, Sun Q and Du G: FOXC1 is associated with estrogen receptor alpha and affects sensitivity of tamoxifen treatment in breast cancer. Cancer Med 6: 275-287, 2017.

13. Sizemore ST and Keri RA: The forkhead box transcription factor FOXC1 promotes breast cancer invasion by inducing matrix metalloprotease 7 (MMP7) expression. J Biol Chem 287: 24631-24640, 2012

14. Wei LX,Zhou RS, Xu HF, Wang JY and Yuan MH: High expression of FOXC1 is associated with poor clinical outcome in non-small cell lung cancer patients. Tumour Biol 34: 941-946, 2013.

15. Chen S, Jiao S, Jia Y and Li Y: Effects of targeted silencing of FOXC1 gene on proliferation and in vitro migration of human non-small-cell lung carcinoma cells. Am J Transl Res 8 3309-3318, 2016.

16. Wang J, Ray PS, Sim MS, Zhou XZ, Lu KP, Lee AV, Lin X Bagaria SP, Giuliano AE and Cui X: FOXC1 regulates the functions of human basal-like breast cancer cells by activating NF-kB signaling. Oncogene 31: 4798-4802, 2012.

17. Xia L, Huang W, Tian D, Zhu H, Qi X, Chen Z, Zhang Y, Hu H, Fan D, Nie Y and Wu K: Overexpression of forkhead box C1 promotes tumor metastasis and indicates poor prognosis in hepatocellular carcinoma. Hepatology 57: 610-624, 2013.

18. Ou-Yang L, Xiao SJ, Liu P, Yi SJ, Zhang XL, Ou-Yang S, Tan SK and Lei X: Forkhead box C1 induces epithelialmesenchymal transition and is a potential therapeutic target in nasopharyngeal carcinoma. Mol Med Rep 12: 8003-8009, 2015.

19. Wang J, Li L, Liu S, Zhao Y, Wang L and Du G: FOXC1 promotes melanoma by activating MST1R/PI3K/AKT. Oncotarget 7 : 84375-84387, 2016.

20. Zhu X, Wei L, Bai Y, Wu S and Han S: FoxC1 promotes epithelial-mesenchymal transition through PBX1 dependent transactivation of ZEB2 in esophageal cancer. Am J Cancer Res 7: 1642-1653, 2017.

21. Huang L, Huang Z, Fan Y, He L, Ye M, Shi K, Ji B, Huang J, Wang $\mathrm{Y}$ and $\mathrm{Li} \mathrm{Q}$ : FOXC1 promotes proliferation and epithelial-mesenchymal transition in cervical carcinoma through the PI3K-AKT signal pathway. Am J Transl Res 9: 1297-1306, 2017.

22. Liu Y, Han L, Bai Y, Du W and Yang B: Down-regulation of MicroRNA-133 predicts poor overall survival and regulates the growth and invasive abilities in glioma. Artif Cells Nanomed Biotechnol 46: 206-210, 2018.

23. Livak KJ and Schmittgen TD: Analysis of relative gene expression data using real-time quantitative PCR and the 2(-Delta Delta C(T)) method. Methods 25: 402-408, 2001
24. Yu H, Xue Y, Wang P, Liu X, Ma J, Zheng J, Li Z, Cai H and Liu Y: Knockdown of long non-coding RNA XIST increases blood-tumor barrier permeability and inhibits glioma angiogenesis by targeting miR-137. Oncogenesis 6: e303, 2017.

25. Wang L, Chai L, Ji Q, Cheng R, Wang J and Han S: Forkhead box protein $\mathrm{C} 1$ promotes cell proliferation and invasion in human cervical cancer. Mol Med Rep 17: 4392-4398, 2018.

26. Xu YY, Tian J, Hao Q and Yin LR: MicroRNA-495 downregulates FOXC1 expression to suppress cell growth and migration in endometrial cancer. Tumour Biol 37: 239-251, 2016.

27. Deng L, Liu T, Zhang B, Wu H, Zhao J and Chen J: Forkhead box $\mathrm{C} 1$ is targeted by microRNA-133b and promotes cell proliferation and migration in osteosarcoma. Exp Ther Med 14: 2823-2830, 2017.

28. Kalluri R and Weinberg RA: The basics of epithelial-mesenchymal transition. J Clin Invest 119: 1420-1428, 2009.

29. Yilmaz M and Christofori G: EMT, the cytoskeleton, and cancer cell invasion. Cancer Metastasis Rev 28: 15-33, 2009.

30. Xu ZY, Ding SM, Zhou L, Xie HY, Chen KJ, Zhang W, Xing CY, Guo HJ and Zheng SS: FOXC1 contributes to microvascular invasion in primary hepatocellular carcinoma via regulating epithelial-mesenchymal transition. Int J Biol Sci 8: 1130-1141, 2012.

31. Clevers $\mathrm{H}$ and Nusse R: Wnt/ $\beta$-catenin signaling and disease. Cell 149: 1192-1205, 2012.

32. Saito-Diaz K, Chen TW, Wang X, Thorne CA, Wallace HA, Page-McCaw A and Lee E: The way Wnt works: Components and mechanism. Growth Factors 31: 1-31, 2013.

33. Anastas JN and Moon RT: WNT signalling pathways as therapeutic targets in cancer. Nat Rev Cancer 13: 11-26, 2013.

34. Li Y, Zhu G, Zeng W, Wang J, Li Z, Wang B, Tian B, Lu D, Zhang X, Gao G and Li L: Long noncoding RNA AB073614 promotes the malignance of glioma by activating Wnt $/ \beta$-catenin signaling through downregulating SOX7. Oncotarget 8: 65577-65587, 2017.

35. Liu X, Wang L, Zhao S, Ji X, Luo Y and Ling F: $\beta$-catenin overexpression in malignant glioma and its role in proliferation and apoptosis in glioblastma cells. Med Oncol 28: 608-614, 2011.

36. Zhang K, Zhang J, Han L, Pu P and Kang C: Wnt/beta-catenin signaling in glioma. J Neuroimmune Pharmacol 7: 740-749, 2012.

37. Mishra S, Choe Y, Pleasure SJ and Siegenthaler JA Cerebrovascular defects in Foxc1 mutants correlate with aberrant WNT and VEGF-A pathways downstream of retinoic acid from the meninges. Dev Biol 420: 148-165, 2016.

38. Savage J, Voronova A, Mehta V, Sendi-Mukasa F and Skerjanc IS: Canonical Wnt signaling regulates Foxc1/2 expression in P19 cells. Differentiation 79: 31-40, 2010. 